\title{
Family planning among undergraduate university students: a CASE study of a public university in Ghana
}

\author{
Fred Yao Gbagbo ${ }^{*}$ (D) and Jacqueline Nkrumah
}

\begin{abstract}
Background: Globally, the rate of unplanned pregnancies among students at institutions of higher education, continue to increase annually despite the universal awareness and availability of contraceptives to the general population. This study examined family planning among undergraduate university students focusing on their knowledge, use and attitudes towards contraception in the University of Education Winneba.
\end{abstract}

Methods: The study was a descriptive cross-sectional survey using a structured self-administered questionnaire. One hundred undergraduate students from the University of Education Winneba were selected using a multistage simple random sampling technique. A Likert scale was used to assess the attitude of the respondents towards family planning methods.

Results: Findings show that the respondents had a positive attitude towards family planning with an average mean score of about 4.0 using a contraceptive attitude Likert scale. Knowledge of contraception, awareness and benefits however do not commensurate contraceptive use among undergraduate students since availability, accessibility and preference influence usage. Emergency Contraception (Lydia) was reported as easy to get contraceptive, hence the most frequently used contraceptive (31\%) among young female students aged 21-24 years who appeared as the most vulnerable in accessing and using contraceptives due to perceived social stigma.

Conclusion: The observation that levels of Family Planning awareness levels do not commensurate knowledge and usage levels calls for more innovative strategies for contraceptive promotion, and Education on the various university campus. The study recommends that public Universities in Ghana should consider a possible curriculum restructuring to incorporate family planning updates. In this regard, a nationwide mixed method study targeting other tertiary institutions including colleges of education in Ghana is required to explore the topic further to inform policy and programme decisions.

Keywords: Family planning, Undergraduate students, University of Education, Winneba, Ghana

\section{Background}

The global incidence of unplanned pregnancies amongst students at higher educational institutions every year continues to increase despite the high awareness and knowledge on regular modern contraceptives and emergency contraceptives among students in higher educational institutions $[1,2]$. Despite the immense contraceptive benefits for students in higher educational institutions [3], there is no direct positive correlation

\footnotetext{
* Correspondence: gbagbofredyao2002@yahoo.co.uk; fygbagbo@uew.edu.gh Department of Health Administration and Education, University of Education Winneba, Faculty of Science Education, P.O. Box 25, Winneba, Ghana
}

between the universal awareness, knowledge and use of contraceptives which challenges global health efforts. The poor utilisation of contraceptives in tertiary institutions is associated with many interrelated factors ranging from personal to institutional setbacks [4]. This eventually contributes to high unplanned pregnancy rates which is estimated to have contributed to about 8 to 30 million annual pregnancies worldwide [5]. Global estimates have also shown that about 210 million pregnancies occur annually across the world. 75 million (or about $36 \%$ ) of the 210 are unplanned or unwanted pregnancies [6]. Students between 18 and 24 years report the

(c) The Author(s). 2019 Open Access This article is distributed under the terms of the Creative Commons Attribution 4.0 International License (http://creativecommons.org/licenses/by/4.0/), which permits unrestricted use, distribution, and 
highest rates of unplanned pregnancies in the world's tertiary institutions $[7,8]$. A situation associated with multiple challenges across the world for countries, academic institutions and the individuals involved [9].

Studies in Africa, have generally documented low knowledge and awareness levels of effective contraceptive use amongst higher educational students [10]. Several factors including age, culture, ethnicity, religion, poor access to contraceptive services, peer pressure and lack of partner support were identified as contributing to the non-utilisation of contraceptives in tertiary institutions [11]. In a study amongst 15 to 24 year old South African women, it was estimated that only $52.2 \%$ of sexually experienced women are using contraceptives [12]. Because $80 \%$ of undergraduate students at higher educational institutions are sexually active, it is important that they have access to safe, accessible and adequate contraceptive services [13].

Although national surveys on family planning [14] have extensively looked at contraceptive uptake in Ghana, little is known about contraceptive up take among students in Ghanaian Universities. This study therefore examines family planning acceptance among students of the University of Education, Winneba in Ghana to compliment national data on family planning.

\section{Methods}

A descriptive cross-sectional study design using a quantitative approach of data collection was adopted. This design was chosen because it fits studies in natural setting, explains phenomena from the view point of persons being studied and produces descriptive data from the respondent own written or spoken words [15].

The study was conducted in the main campus of the University of Education, Winneba. The university was established in 1992 to train middle and top-level manpower for the educational sector of Ghana. It has four main satellite campuses, (Winneba and Ajumako in the Central Region of Ghana, Kumasi, and Mampong campuses in Ashanti Region of Ghana). The Winneba campus has three smaller campuses with five faculties (Faculty of social science education, Faculty of languages, Faculty of science education, Faculty of educational studies and School of creative Arts).

The study population comprised134 'non-resident' undergraduate students of the University of Education Winneba, between ages 17-36 years in 2017 who were registered with an accommodation agent in Winneba that looks for accommodation for students who are unable to obtain university accommodation on campus. This population and age group was selected because anecdotal evidence shows that being a 'non-resident' student has the likelihood of making one vulnerable to sexual exploitations whilst seeking accommodation off campus. This age group was considered to be the reproductive age group of the undergraduate students. Because the University only guarantees on campus residential accommodation for only selected first year students, those who do not get the university's residential accommodation are likely to be victims of sexual exploitations in the Effutu Municipality where the university is situated. This challenge is due to the scarcity of accommodation coupled with the high rent charges for rented accommodation. As per the estimated sample size calculated, a total of one hundred respondents comprising twenty from each of the five faculties were sampled at random to include both male and female students from the various course levels. This was done to ensure a true representation of the student population for the study.

A multistage sampling technique was used to select these respondents for the study. The first stage involved half day orientation of 2 field assistants (male and female) the estimation of the undergraduate students' population who falls in this category during the period of the study. The second stage involved sample size calculation using an online Raosoft sample size calculator at 95\% confidence interval, $5 \%$ margin of error and $50 \%$ response distribution [16]. In terms of the figures, the sample size $n$ and margin of error $E$ are given by:

$$
\begin{aligned}
x & =Z\left({ }^{c} / 100\right)^{2} r(100-r) n={ }^{N x} /\left((N-1) \cdot E^{2}+x\right) E \\
& =\operatorname{Sqrt}[(N-n) x / n(N-1)]
\end{aligned}
$$

Where $\mathrm{N}$ is the population size (134), $\mathrm{R}$ is the fraction of responses that the study is interested in, and $\mathrm{Z}(\mathrm{c} / 100)$ is the critical value for the confidence level c. The estimated number of respondents were then randomly sampled and contacted for participating in the in the third stage of the study. The fourth stage of the study involved distributing the developed questionnaires to consented students.

A Structured Questionnaire (See Additional file 1), designed by the authors was used to solicit responses from respondents. The questionnaire was exploratory in nature with both opened and closed ended questions to help respondents easily share their views. The questionnaire was pre-tested among 20 potential respondents from a different university. The Contraceptive Attitude Likert scales was used to measure attitudes by asking people to respond to series of statements about the topic, in terms of the extent to which they agree or disagree with them. Thus, tapping into the cognitive and affective components of attitudes [17]. The Contraceptive Attitude Scale presented positive and negative statements to elicit for responses that portray participants' attitudes relating to contraception.

One hundred questionnaires were administered, and all the answers to a particular question were arranged, numbered and responses were coded. The responses 
Table 1 Background characteristics of respondents

\begin{tabular}{|c|c|c|}
\hline Variable & Number (No) & Percentage (\%) \\
\hline \multicolumn{3}{|l|}{ Age (in years) } \\
\hline $17-20$ & 9 & 9.0 \\
\hline $21-24$ & 47 & 47.0 \\
\hline $25-28$ & 31 & 31.0 \\
\hline $29-32$ & 4 & 4.0 \\
\hline $33-36$ & 2 & 2.0 \\
\hline$>36$ & 7 & 7.0 \\
\hline \multicolumn{3}{|l|}{ Marital status } \\
\hline Married & 3 & 3.0 \\
\hline Cohabitation & 5 & 5.0 \\
\hline Divorced & 1 & 1.0 \\
\hline Single & 86 & 86.0 \\
\hline Widow/widower & 1 & 1.0 \\
\hline Other & 4 & 4.0 \\
\hline \multicolumn{3}{|l|}{ Religious affiliation } \\
\hline Christian & 84 & 84.0 \\
\hline Islamic & 12 & 12.0 \\
\hline Traditional & 0 & 0.0 \\
\hline Other & 4 & 4.0 \\
\hline \multicolumn{3}{|l|}{ Gender } \\
\hline Male & 66 & 66.0 \\
\hline Female & 30 & 30.0 \\
\hline Other & 4 & 4.0 \\
\hline \multicolumn{3}{|l|}{ Employment status } \\
\hline Employed & 11 & 11.0 \\
\hline Unemployed & 78 & 78.0 \\
\hline No response & 11 & 11.0 \\
\hline \multicolumn{3}{|c|}{ Number of living children } \\
\hline 0 & 86 & 86.0 \\
\hline 1 & 5 & 5.4 \\
\hline 2 & 1 & 1.0 \\
\hline$>2$ & 8 & 8.0 \\
\hline \multicolumn{3}{|l|}{ Level in programme } \\
\hline 100 & 26 & 26.0 \\
\hline 200 & 44 & 44.0 \\
\hline 300 & 25 & 25.0 \\
\hline 400 & 5 & 5.0 \\
\hline \multicolumn{3}{|l|}{ Ethnicity } \\
\hline Akan & 64 & 64.0 \\
\hline Ewe & 6 & 6.0 \\
\hline Ga-Adangbe & 6 & 6.0 \\
\hline Mole-Dagbani & 11 & 11.0 \\
\hline Guan & 3 & 3.0 \\
\hline Grusi & 1 & 1.0 \\
\hline
\end{tabular}

Table 1 Background characteristics of respondents (Continued)

\begin{tabular}{lll}
\hline Variable & Number (№) & Percentage (\%) \\
\hline Others & 9 & 9.0 \\
History of pregnancy & & \\
Ever pregnant & 13 & 13.0 \\
Never pregnant & 77 & 77.0 \\
No response & 10 & 10.0 \\
\hline
\end{tabular}

Source: Field data 2017

were again listed and grouped, putting those with the same code together. Data analysis was done after data had been collected and checked for completeness and accuracy. The Statistical Package for Social Sciences (SPSS) software version 23 was used for data analysis. Frequencies, percentages and bar charts were used to describe the data in multivariable tables.

\section{Ethics approval and consent to participate}

An approval was obtained from the University prior to data collection. Written consent for participation and publication of findings were also obtained from respondents after the purpose, objectives and potential risk and benefits inherent in the study had been explained to them. Prior to the commencement of the study, the research protocol was presented at the bi-weekly academic research seminars of the Faculty of Science Education, University of Education, Winneba. The seminar brought together lectures of the Faculty (equivalent to an ethical review meeting) who critiqued and reviewed the study protocol for ethical suitability and sound methodology. All participants in the study were given the opportunity to ask questions about the study at any stage, and to withdraw from the study at any time. All data collected were kept confidential and data was analysed anonymously to ensure that results were not traceable to individual respondent.

\section{Results}

The overall response rate for the study was $100 \%$. Table 1 presents the background characteristics of respondents. A large number of the respondents were within the age categories of 21 to 24 years and 25 to 28 years. Most of the respondents were single $(86.0 \%)$ and have no children (86.0\%).

Table 2 present results of students' knowledge, information sources and reasons for accepting or not accepting family planning. Family planning awareness and knowledge among students was a key consideration in the study.

About $94 \%$ of respondents answered yes to whether they have ever heard about family planning. Although majority (61\%) of the respondents believed FP is helpful, 
Table 2 Family Planning Knowledge, Information Sources and Reasons for Family Planning Acceptance among Student

\begin{tabular}{|c|c|c|c|c|c|c|}
\hline \multirow[t]{2}{*}{ Details of issues investigated } & \multicolumn{6}{|c|}{ Responses } \\
\hline & $\overline{\text { Yes }}$ & $\%$ & No & $\%$ & NR & $\%$ \\
\hline Ever heard of family planning & 94 & 94.0 & 2 & 2.0 & 4 & 4.0 \\
\hline Can you get pregnant when using withdrawal method? & 67 & 67.0 & 25 & 25.0 & 8 & 8.0 \\
\hline Is family planning helpful? & 61 & 61.0 & 25 & 25.0 & 14 & 14.0 \\
\hline Will you recommend FP to a friend or relative? & 69 & 69.0 & 20 & 20.0 & 10 & 10.0 \\
\hline \multicolumn{7}{|l|}{ Meaning of family planning } \\
\hline Don't know & 9 & 9.0 & & & & \\
\hline Measures to reduce child birth & 21 & 21.0 & & & & \\
\hline Measures to prevent unwanted pregnancy & 14 & 14.0 & & & & \\
\hline Measures to space child birth & 17 & 17.0 & & & & \\
\hline Measures to reduce number of children and unwanted pregnancy & 2 & 2.0 & & & & \\
\hline Measures to reduce unwanted pregnancy, space and reduce childbirth & 33 & 33.0 & & & & \\
\hline Others & 4 & 4.0 & & & & \\
\hline Total & 100 & 100 & & & & \\
\hline \multicolumn{7}{|l|}{ Sources of family planning information } \\
\hline Don't know & 6 & 6.0 & & & & \\
\hline Television & 31 & 31.0 & & & & \\
\hline Books & 14 & 14.0 & & & & \\
\hline Radio & 9 & 9.0 & & & & \\
\hline Health worker & 11 & 11.0 & & & & \\
\hline Friend & 2 & 2.0 & & & & \\
\hline Social media & 27 & 27.0 & & & & \\
\hline Total & 100 & 100 & & & & \\
\hline \multicolumn{7}{|l|}{ Reasons for family planning } \\
\hline Don't know & 1 & 1.6 & & & & \\
\hline Help prevent unwanted pregnancies & 20 & 32.8 & & & & \\
\hline FP promote small family size & 16 & 26.2 & & & & \\
\hline FP helps in planning and catering for children & 14 & 23.0 & & & & \\
\hline Prevent STIs & 1 & 1.6 & & & & \\
\hline FP reduce family expenses & 5 & 8.3 & & & & \\
\hline FP reduce over population & 2 & 3.3 & & & & \\
\hline FP reduces school drop outs & 1 & 1.6 & & & & \\
\hline Others & 1 & 1.6 & & & & \\
\hline Total & 100 & 100 & & & & \\
\hline \multicolumn{7}{|l|}{ Reasons against family planning } \\
\hline Don't know & 4 & 8.0 & & & & \\
\hline Have not used some before & 7 & 28.0 & & & & \\
\hline Negative side effect & 5 & 20.0 & & & & \\
\hline FP is for only married people & 1 & 4.0 & & & & \\
\hline FP can cause conditions such as fibroid & 2 & 8.0 & & & & \\
\hline FP causes premature menopause & 1 & 4.0 & & & & \\
\hline The bible is against FP & 2 & 8.0 & & & & \\
\hline FP causes barrenness & 1 & 4.0 & & & & \\
\hline FP is not reliable, it can fail & 2 & 8.0 & & & & \\
\hline Total & 100 & 100 & & & & \\
\hline
\end{tabular}


about (67.0\%) knew that one could get pregnant by relying on the withdrawal method. It appears most students would be committed to family planning uptake if services are made available. This is evident by $69 \%$ of them responding in the affirmative when asked whether they will encourage their family or friends to use family planning services in the University.

Having knowledge of family planning does not necessarily translate into utilization since the respondents had varied reasons for and against using family planning. Respondents who were of the view that FP was not helpful (25.0\%) had either not used any family planning method before $(28.0 \%)$ or had ever suffered unpleasant negative side effects $(20.0 \%)$ following family planning usage or believed the bible is against family planning (2.0\%).

Figure 1 presents respondents' attitudes towards family planning as estimated using the Contraceptive Attitude Scale. The overall population surveyed had a positive attitude towards family planning (average mean attitude score was about 4.0 out of 5.0).

There were however some divergent responses to the questions relating to contraceptive use. Some of these include:

- 'I will not have sexual intercourse if no contraceptive method was available'

- 'I will use contraceptives even if my partner does not want me to use it'

- 'I will not use contraceptives because they encourage promiscuity'

When the respondents were asked if they have ever used any FP method before, the majority of the respondents (67.0\%) mentioned that they had never used any FP method. Regarding availability of family planning service when needed, about $64.0 \%$ of the respondents indicated that family planning services are always available in chemical shops and from colleges on campus when needed. About $58 \%$ will use FP methods in the future. Regarding information on source of family planning services if required, most of the respondents (85\%) knew where to get family planning services in their communities (Table 3). Young Female students aged 21-24 years were the most vulnerable in accessing and using contraceptives due to perceived social stigma relating to a female student buying a contraceptive.

Table 4 documents the various family planning choices and reasons for the choices. About $65.0 \%$ of respondents reported that they primarily use contraceptives to prevent pregnancy and usually use a contraceptive before sexual intercourse (34.0\%). When asked to select the primary methods of contraception frequently used, Emergency Contraception was the most reported frequently used (51\%) contraceptive followed by male condoms (34.0\%). Various side effects associated with some FP methods were also reported. Some respondents were of the view that there should be education for students on the risk and benefits of FP methods for effective use. Others believed FP should not be tolerated among students because it can be abused leading to major health problems that could affect studies. Knowledge of contraception, awareness and benefits however do not commensurate contraceptive use among undergraduate students since availability, accessibility, preference and cost of contraceptives hinders use.

\section{Discussion}

This study examined family planning among undergraduate university students focusing on their knowledge, use and attitudes towards family planning in the University of Education Winneba. The study was a descriptive cross-sectional survey using a structured self-administered questionnaire for data collection. Various findings obtained from the study had reproductive health programme and policy implications. Informal sources of family planning information such as friends, peers and relatives were common information sources

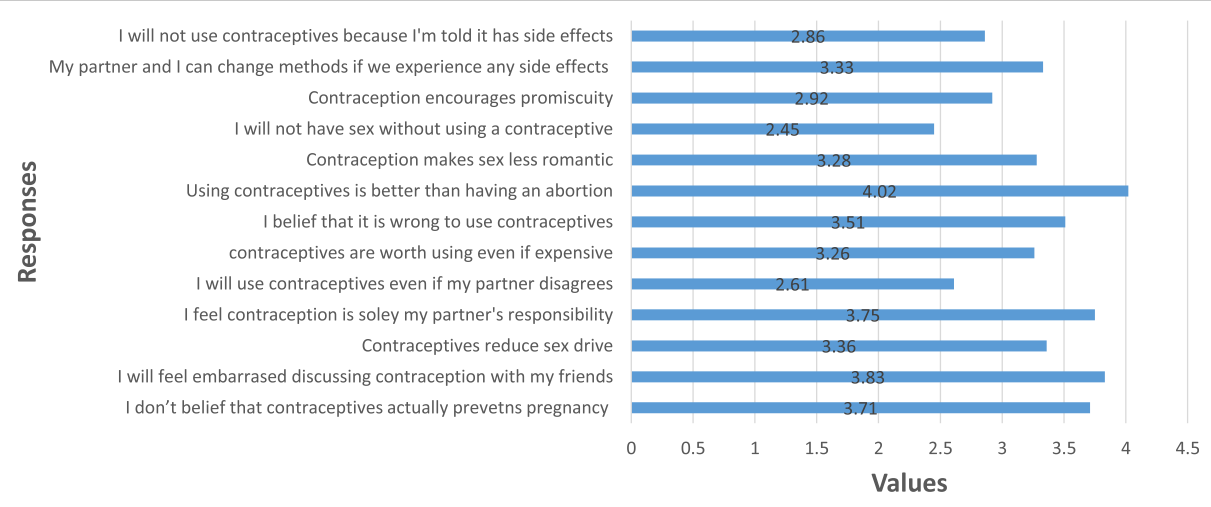

Fig. 1 Attitude towards Family Planning 
Table 3 Source of Family planning services, Utilization and effects of FP methods

\begin{tabular}{|c|c|c|c|c|c|c|}
\hline \multirow[t]{2}{*}{ Variable } & \multicolumn{3}{|c|}{ Number } & \multicolumn{3}{|c|}{ Percentage (\%) } \\
\hline & Yes & No & No response & Yes & No & No response \\
\hline Have you used any FP method before & 29 & 67 & 4 & 29.0 & 67.0 & 4.0 \\
\hline Do you always have access to FP in your area? & 66 & 27 & 7 & 66.0 & 27.0 & 7.0 \\
\hline Do you know where to get FP services by yourself when required? & 85 & 12 & 3 & 85 & 12 & 3 \\
\hline Have you ever experienced any side effect(s) from any of the FP methods used? & 10 & 69 & 21 & 10.0 & 69.0 & 21.0 \\
\hline Do you still use FP services? & 29 & 50 & 21 & 29.0 & 50.0 & 21.0 \\
\hline Do you intend using FP methods in the future & 58 & 31 & 11 & 58.0 & 31.0 & 11.0 \\
\hline
\end{tabular}

for young people [18] but yet prone to misconceptions, distortions and half-truths. Other studies ranked the family (parents, brothers and sisters) as the lowest source of information on sexuality [19-21]. These findings are similar to those reported in the current study that high level of awareness (94.0\%) of contraceptives is noted among university students.

An observation that a large number of the respondents were within the age categories of 21 to 24 years and 25 to 28 years of which most $(86.0 \%)$ were single and have no children $(86.0 \%)$, is an indication that current university students are relatively young and unmarried. A situation that predisposes them to sexual exploitations and requires knowledge on family planning methods to enable them make informed decision and choices regarding their reproductive intentions. Family planning awareness and knowledge among students was a key consideration in the study. The majority (94\%) of respondents indicating that they have ever heard about family planning shows a near universal awareness of family planning methods. This is in line with national reports on family planning awareness in Ghana and a significant departure from many other studies which tended to focus on awareness alone or translate awareness to knowledge [22, 23]. Understanding the methods and benefits of contraception are critical to having motivated users. It has also been noted that motivation is one of the important factors in minimizing failure rates in the utilization of contraception [24]. From previous research findings [25-27] it was established that the most commonly used Family Planning methods among students were short term methods predominantly, condoms, oral contraceptives and withdrawal methods. This confirms finding of other studies that students had little knowledge about effective contraceptive methods [28]. In the current study, a remarkable percentage (25\%) did not know that pregnancy could occur when one relying solely on withdrawal method. Also about $21.0 \%$ of respondents did not know what oral contraceptive pills do, and some $3 \%$ also said oral contraceptive pill prevents Sexually Transmitted Infections (STIs). It was surprising to note in this era of increasing STIs that about $2 \%$ of respondents' from a tertiary institution belief a single condom can be reused many times if washed and dried.

At the tertiary level, one would have expected that all respondents would have known the implications of unprotected sexual intercourse. However the study finding that about (61\%) of the respondents believed family planning is helpful implies that there are some other students who don't belief in family planning hence having unprotected sexual intercourse. Although accessibility to family planning methods on campus in this study was very high $(66.0 \%)$, results from other similar studies were to the contrary $[29,30]$. This therefore suggests that if students know the benefits and how to use contraceptives, they will not experience unwanted pregnancies and its associated consequences of unsafe abortion complications, disruption in academic work and possible death. Contraceptive education is a component of sex education and is one of the proven approaches to prevent risky sexual behaviour and must be introduced on

Table 4 Family planning choices and reasons for the choices

\begin{tabular}{|c|c|c|c|c|c|c|c|c|c|c|c|c|c|c|c|c|}
\hline \multirow{3}{*}{$\begin{array}{l}\text { Primary reason } \\
\text { for choosing a } \\
\text { FP method }\end{array}$} & \multicolumn{16}{|c|}{ Family Planning Choices } \\
\hline & \multicolumn{2}{|c|}{ Condoms } & \multicolumn{2}{|c|}{ Abstinence } & \multicolumn{2}{|c|}{ Injectable } & \multicolumn{2}{|c|}{ Oral contraceptives } & \multicolumn{2}{|c|}{ implant } & \multirow{2}{*}{$\begin{array}{l}\text { Withdrawal } \\
\text { No }\end{array}$} & \multicolumn{3}{|c|}{ calendar } & \multicolumn{2}{|c|}{ Emergency contraception } \\
\hline & No & $\%$ & No & $\%$ & No & $\%$ & No & $\%$ & No & $\%$ & & $\%$ & No & $\%$ & No & $\%$ \\
\hline Number of responses & 23 & 34.0 & 3 & 7.0 & 0 & 0.0 & 1 & 2.6 & 0 & 0.0 & 0 & 0.0 & 0 & 0.0 & 65 & 51.0 \\
\hline Easy to get & 22 & 51.2 & 0 & 0.0 & 1 & 20.0 & 5 & 27.8 & 0 & 0.0 & 0 & 0.0 & 0 & 0.0 & 43 & 31.0 \\
\hline Easy to use & 4 & 9.3 & 1 & 16.7 & 2 & 40.0 & 5 & 27.8 & 1 & 10.0 & 0 & 0.0 & 2 & 66.7 & 0 & 0.0 \\
\hline Effective to use & 3 & 7.0 & 1 & 16.6 & 2 & 40.0 & 6 & 33.3 & 0 & 0.0 & 0 & 0.0 & 0 & 0.0 & 1 & 10.0 \\
\hline No side effect & 11 & 25.6 & 4 & 66.7 & 0 & 0.0 & 1 & 5.6 & 0 & 0.0 & 1 & 10.0 & 1 & 33.3 & 0 & 0.0 \\
\hline
\end{tabular}


university campuses to guide students' family planning choices.

Additionally, findings also shows that there are some students about $(67.0 \%)$ at the university who knew that one could get pregnant by relying on the withdrawal method yet that is their preferred family planning methods. Various studies [31, 32] have explained this observation further by indicating that some adolescents girls feel that a partner's use of condom suggest that they (the girls) might be classified as unclean, likened to commercial sex workers or seen as engaging in extra-relationship sexual activities if they negotiate for condom use during sexual intercourse. The perception of 'I trust my partner so no need for condom use' further explains the frequency of withdrawal methods being a regular family planning method on campus.

Generally, it appears most students were committed to family planning uptake if services are made available as evident by about $69 \%$ of them responding in affirmative when asked whether they will encourage their family or friends to use family planning services in the University. This observation is positive for enhanced family planning service delivery on university campuses to meet the needs of students. Contrary to this observation are those of similar studies which reported that Student frown on invasive family planning methods [33, 34]. The distinction between invasive and non-invasive methods bothers on factors such as availability of method, ease of use and adherence to instructions of a health professional to use the method.

Respondents outlined various sources of family planning information of which television adverts constituted the most reported (31\%) source of information. This observation is quite worrying since anecdotal evidence from university campuses shows that majority of student rarely have and watch televisions whist on the various campuses. It will therefore be very important and useful to devise inno vative ways of educating students on family planning methods whilst on campus.

A finding that having knowledge of family planning does not necessarily translate into usage is very revealing and of public health importance. As it would have been expected, using a method is the surest way of explaining its relevance. However in this study, respondents who were of the view that family planning was not helpful had never used any family planning method before (28.0\%). It is there important to use of family planning satisfied client for contraceptive education and promotion on University campuses to ensure the desired positive results. These are students who are likely to positively influence their sexually active peers on contraceptive use since they are likely to say: 'I will not have sexual intercourse if no contraceptive method was available' or 'I will use contraceptives even if my partner does not want me to use it' as reported in the study.

Regarding information on source of family planning services if required, most of the respondents (85\%) knew where to get family planning services in their communities. For availability of family planning services when needed, about $64.0 \%$ of the respondents indicated that family planning services are always available in chemical shops and from colleges on campus when needed. The obvious indicated sources of contraceptives on campus (i.e., chemical shops and peers) do not provide varying choice of services there by limiting students to short term and less effective family planning methods. It is encouraging noting that about $58 \%$ of respondents will use FP methods in future. This is an indication of them understanding the importance of family planning to studies as about $65.0 \%$ of respondents reported primarily using contraceptives to prevent pregnancy and usually use a method before sexual intercourse (34.0\%) despite the various side effects associated with some FP methods reported.

Knowledge of contraception, awareness and benefits however do not commensurate contraceptive use among undergraduate students since availability, accessibility and preference influence usage. Emergency Contraception (Lydia) was reported as easy to get contraceptive, hence the most frequently used contraceptive (31\%) among young female students aged 21-24 years who appeared as the most vulnerable in accessing and using contraceptives due to perceived social stigma. This observation shows that Students always have a unique view on issues especially those in youthful ages. It is therefore important to incorporate their views in family planning programming. The observation that some respondents were of the view that there should be education for students on the risk and benefits of family planning methods for effective use is in the right direction and worth exploring. There are also concerns of values clarification as observed by the findings that some respondents believed family planning should not be tolerated among students because it can be abused leading students to becoming promiscuous or suffering major health problems that will affect their studies.

The following recommendations are therefore being suggested to chart a way forward:

- Public Universities in Ghana should consider a possible curriculum restructuring to incorporate family planning lessons in the academic programme for students to acquire current knowledge in this area. The reproductive health education programs should include the importance of using dual contraceptive methods as a means to prevent HIV transmission and pregnancy, as well as information on how to 
make an informed decision relating to contraceptive choices.

- The Winneba Municipal Health Directorate should incorporate family planning education on campuses into their public health programs.

- The university health service should also create friendly environment for student to access family planning services and also collaborate with the student body to organise programmes to educate the students on family planning methods.

- The student representative council (SRC) should also make family planning education a part of their programs and in collaboration with the university health services organise free STI testing and family planning counselling at least once yearly.

- A nationwide mixed method study targeting other tertiary institutions particularly colleges of education in Ghana is required to explore the topic further for a national decision on contraceptive security in tertiary institutions in Ghana.

\section{Conclusions}

Findings of this study showed that the awareness of family planning among the students was high. However, levels of contraceptive usage were low and restricted to the short term, Emergency Contraceptives and redrawal methods. The perception by a cross-section of respondents (although by a small group) that condoms can be reused more than once confirms the gross ignorance of contraception practices and the potential risk to STIs and Pregnancy. Additionally, Emergency Contraception (Lydia) being reported as easy to get contraceptive, hence the most frequently used contraceptive (31\%) among young female students aged 21-24 years, is an indication that this student population appeared as the most vulnerable in accessing and using contraceptives due to perceived social stigma and must therefore be the prime focus of contraception education and services on the University. The University of Education being a tertiary institution mandated to train teachers, is expected to ensure that its students have accurate and current information on family planning methods relevant to educate others. This is an obvious gap that requires policy decisions at all levels and FP education interventions at the tertiary level of education in Ghana.

\section{Additional file}

Additional file 1: Appendix I-Questionaire. The appendix I contains the structured question developed by the authors and used for data collection in the study. (DOCX $23 \mathrm{~kb}$ )

Abbreviations

FP: Family planning; SPSS: Statistical Package for Social Sciences; STI: Sexually Transmitted Infections; UEW: University of Education Winneba

\section{Acknowledgements}

The authors are grateful to the University of Education Winneba, Faculty of Science Education for the valuable inputs in shaping the manuscript. Many thanks also to the respondents for their corporation during data collection.

\section{Funding}

The entire study was jointly funded by the authors.

\section{Availability of data and materials}

The raw data and any material related to the study is available upon reasonable request from the corresponding author.

Authors' contributions

FYG conceptualized and designed the study. JN supervised the data collection, analysis and drafted the initial report. Both authors discussed the report, edited it together and approved the manuscript for final submission.

\section{Ethics approval and consent to participate}

The research protocol was first presented at the Faculty of Science Education, University of Education, Winneba periodic academic seminars for review and approval for methodology and ethical suitability. This seminar, brings together senior members and research fellows of the University to review research protocols and papers meant for publication and conferences. Approval for data collection and publication were subsequently granted following the full incorporation of comments received from the seminar presentation.

Prior to data collection, verbal and written permissions were sought from the respondents to participate in the study. The permission was granted after the objectives and nature of the study were satisfactorily explained to the respondents.

\section{Consent for publication}

The respondents consented for the study to be published but assured of anonymity before administering the questionnaire. The respondents were also given the opportunity to ask questions about the study at any stage, and to withdraw from the study at any time.

\section{Competing interests}

The authors declare that they have no competing interests in this study.

\section{Publisher's Note}

Springer Nature remains neutral with regard to jurisdictional claims in published maps and institutional affiliations.

Received: 1 August 2017 Accepted: 2 January 2019

Published online: 17 January 2019

References

1. World Health Organization (WHO). (2013): Family planning fact sheet Retrieved from http://www.who.int/mediacentre/factsheets/fs351/en/ United Nations. (2011). The millennium development goals report. Retrieved from www.un.org/millenniumgoals/11_MDG\%20Report_EN.pdf

2. Maja TMM, Ehlers VJ. Contraceptive practices in northern Tshwane, Gauteng Province. Health SA Gesondheid. 2004;9(4):42-52 https://doi.org/10.4102/ hsag.v9i4.179.

3. Ersek, J.L., Brunner Huber, L.R., Thompson, M.E. \& Warren-Findlow, J., (2011): 'Satisfaction and discontinuation of contraception by contraceptive method among university women', Matern Child Health J 15, 497-506. PMID: 20428934, https://doi.org/10.1007/s10995-010-0610-y 
4. Hubacher, D., Ifigeneia, M. \& McGinn, E., (2008): 'Unintended pregnancy in sub-Saharan Africa: magnitude of the problem and potential role of contraceptive implants to alleviate it', Contraception 78, 73-78. PMID: 18555821, https://doi.org/10.1016/j.contraception.2008.03.002

5. Adhikari, R., (2009): 'Factors affecting awareness of emergency contraception among college students in Kathmandu, Nepal', BMC Women's Health 9, 27. PMID: 19761598, https://doi.org/10.1186/1472-6874-9-27

6. Singh, S., Sedgh, G., \& Hussain, R. (2010) "Unintended pregnancy: worldwide levels, trends, and outcomes"Studies in family planning 41, no. 4:241-250.

7. Esere MO. Effect of sex education programme on at-risk sexual behaviour of school going adolescents in Ilorin, Nigeria. Africa health science. June. 2008; 8(2):120-5.

8. Trieu, S.I., Shenoy, D.P., Bratton, S. \& Marshak, H.H., (2011): 'Provision of emergency contraception at student health centers in California community colleges', Womens Health Issues 21(6), 431-437. PMID: 21703870, https://doi. org/10.1016/j.whi.2011.04.011

9. Vermaas, L., (2010). 'Dealing with unplanned pregnancies and abortions amongst tertiary students', paper presented at the 6th African Conference on Psychotherapy in Uganda, Kampala, Uganda, 14-16 December, viewed 13 February 2013, from http://www.tut.ac.za/News/Pages/pregnancies.aspx.

10. Ahmed, F.A., Moussa, K.M., Petterson, K.O. \& Asamoah, B.O., (2012), 'Assessing knowledge, attitude, and practice of emergency contraception: A cross sectional study among Ethiopian undergraduate female students', BMC Public Health, 12, 110, viewed 06 March 2015, from http://biomedcentral. com/1471-2458/12/110 Page 7 of Original Research http://www.curationis. org.za doi:https://doi.org/10.4102/curationis.v38i2.1535.

11. Golbasi Z, Tugut N, Erenel AS. Knowledge and opinions of Turkish University students about contraceptive methods and emergency contraception. Sex Disabil. 2012;30:77-87 https://doi.org/10.1007/s11195-011-9227-3.

12. MacPhail, C., Pettifor, A.E., Pascoe, S. \& Rees, H.V., (2007): 'Contraception use and pregnancy among 15-24 year old south African women: a nationally representative cross-sectional survey', BMC Med 5, 31. PMID: 17963521, https://doi.org/10.1186/1741-17015/5/31

13. Bryant, K.D., (2009): 'Contraceptive use and attitudes among female college students', Journal of ABNF 20(1), 12-16. PMID: 19278182.

14. Ghana Statistical Service (2014). Ghana Demographic and Health Survey Report.

15. Akintade OL, Pengpid S, Peltzer K. Awareness and use of and barriers to family planning services among female university students in Lesotho' south African journal of Gynaecology 17(3), 72-78.McNab C, (2009): what social media offers to health professionals and citizens. Bull World Health Organ. 2011;87:566.

16. Raosoft Sample Size Calculator Accessed on $2^{\text {nd }}$ July, 2012 from http:// www.raosoft.com/samplesize.html

17. Tilahun D, Assefa T, Belachew T. Knowledge, attitude and practice of emergency contraceptives among Adama University female students. Ethiopia Journal of Health Sciences November. 2010;20(3):195-202.

18. Sigereda G., (2004): Barriers to use contraceptive among adolescents in the city of Addis Ababa. Master's theses.

19. Abiodun MO, Olayinka PB. Sexual activity and contraceptive use among female students of tertiary educational institutions in Illorin. Nigeria Contraception. 2009;79(2):146-9.

20. Mehra, D., Agardh, A., Petterson, K.O. \& Ostergren, P.O., (2012): 'Non-use of contraception: determinants among Ugandan university students', Glob Health Action 5, 18599. PMID: 23058273, https://doi.org/10.3402/gha.v5i0.18599

21. Tayo A, Akinola O, Babatunde A, Adewunmi A, (2011): Contraceptive knowledge and usage among female school students in Lagos, south-West Nigeria. Journal of public health and epidemiology January, 3 (1), pg. 34-37.

22. Bafana T. Factures influencing contraceptive use and unplanned pregnancy in a South African population. MA thesis: Witwatersrand University; 2010.

23. Egarter C, Grimm C, Ahrendt KNH-J, Bitzer J, Ehlers VJ, Zvavemwe Z. Experiences of a community based contraceptive programme. Int J Nurs Stud. 2009;46(3):302-9

24. World Health Organization, WHO. Programming for adolescent health and development: report of a WHO/UNFPA/UNICEF study group on programming for adolescent health. Technical report. Geneva: WHO; 1999. p. 886.

25. Cadmus E, Owoaje E. Patterns of contraceptive use among female undergraduates in the University of Ibadan, Nigeria. The Internet Journal of Health. 2009;10(2).

26. John, H. Contraceptive Knowledge, Perceptions and use among adolescents journal of Sociol Res 2012; 3(2):170-180. 25-34.
27. Appiah-Agyekum, N.N. \& Kayi, E.A. (2013). Students' Perceptions of Contraceptives in University of Ghana, 7(1): 39-44. Beware of AIDS (BAWA), Offinso-Ashanti, Ghana International Conference on AIDS. International Conference of AIDS 12: 1005 (abstract number 60018).

28. Roberts, C., Moodley, J. \& Esterhuizen, T., (2004): Emergency contraception: knowledge and practices of tertiary students in Durban, South Africa', Journal of Obstetrics and Gynaecology 24(4), 441-445. PMID: 15203588 , https://doi.org/10.1080/0144361040001685619

29. Canadian Statistics, (2010): Trends in the Age Composition of College and University Students and Graduates www. Statcan.gc.ca Accessed 1/4/14.

30. Dreyer G. Contraception: a south African perspective. Pretoria: Van Schaik Publishers; 2012

31. Adegoke AA. Adolescents in Africa: Revealing the problems of teenagers in contemporary African society. Ibadan, Hadassah Publishing; 2003.

32. Omo-Aghoja LO, Omo-Aghoja WW, Aghoja CO, Okonofua FE, Aghedo O, Umueri C, Otayohwo R, Feyi-Waboso P, Onowhakpor EA, Inikori KA. Factors associated with the knowledge, practice and perceptions of contraception in rural southern Nigeria. Ghana Med J. 2009;43(3):115-21.

33. McMahon S, Hansen L, Mann J, Sevigny C, Wong T, Roache M. Contraception. BMC Womens Health. 2004:4(Suppl1):S25.

34. Clements $\mathrm{S}$, Madise N. Who is being served least by family planning providers? A study of modern contraceptives use in Ghana, Tanzania and Zimbabwe. Afr J Reprod Health. 2004;8:124.

Ready to submit your research? Choose BMC and benefit from:

- fast, convenient online submission

- thorough peer review by experienced researchers in your field

- rapid publication on acceptance

- support for research data, including large and complex data types

- gold Open Access which fosters wider collaboration and increased citations

- maximum visibility for your research: over $100 \mathrm{M}$ website views per year

At BMC, research is always in progress.

Learn more biomedcentral.com/submissions 